\title{
Redefining the Role of the Sound Engineer: Applying the Theories of Cage, Schafer, and Lomax Towards Establishing a Critical Cultural Approach to Sound Engineering
}

\author{
Jonathan Pluskota \\ University of Southern Mississippi \\ This paper was presented at the 2019 International Summit of the \\ Music \& Entertainment Industry Educators Association
}

March 21-23, 2019

https://doi.org/10.25101/19.29

\section{Abstract}

Within mainstream media, more specifically music, sound engineers and producers seek recording environments that are acoustically optimal for recording musical artists and sound. From the minimizing of noise to the isolation of instruments and the multitrack recording process itself, the focus of the session often favors technical and performance precision over concern for more qualitative attributes such as emotion and artist-production environment interaction. As a result, recordings tend to become clinical-a specific studio is chosen for its sound quality (reverberation, delay, and frequency response, to name a few) that changes only when the instrument within the room changes. Ironically, it is often a practice by producers and sound engineers alike to add artificial sonic elements post-tracking as a method to alter the production rather than capitalizing on the natural acoustical and sonic environments.

Though resulting productions may fit the commercial needs of the entertainment industry and consumers, it is argued that limiting the role of the sound engineer to such a clinical studio approach eliminates the potential for capturing critical cultural information that aesthetically rich location-based recordings can provide. Such attributes have the potential to transform the musical performance, the production itself, and the consumer listening experience. It is suggested that additional captured acoustic artifacts act as environmental cues and are necessary to documenting and developing an understanding of the culture of musicians and the production process.

Through such a critical cultural approach, this paper discusses how selected works, contributions, and perspectives of three influential sound scholars-John Cage, R. Murray Schafer, and Alan Lomax — can be integrated into sound en- gineering pedagogy and more broadly, to the future of sound engineering and the preservation of culturally relevant sonic elements. As a result, a model is presented, followed by a series of examples and recommendations. The role of the sound engineer is redefined to reflect the newly proposed critical cultural approach to sound engineering. By adopting this definition and approach, the performance, recording process, and consumption can be transformed into unique experiences comprised of important cultural information and rich sonic aesthetics as a result of the interaction between person, environment, and sound.

Keywords: sound engineering, recording, location recording, John Cage, Alan Lomax, R. Murray Schaffer, sound culture, acoustic ecology

\section{Introduction}

The music industry, as a subset of the broader entertainment and media industries, is in need of help. It is not that the industry is on the verge of some catastrophic collapse; In fact, given the drastic changes that were forced upon it by digital media at the beginning of the twenty-first century, the industry has recovered nicely. Not only was the music industry projected to grow just under two percent per year between 2014 and 2019 (Crompton 2014), but music has been the top entertainment choice for ninety-three percent of Americans (The Nielsen Company 2014), who are listening to more music now than in previous years, spending just over 32 hours per week listening to music across an average of 3.4 devices (The Nielsen Company 2017).

Though the business of the music industry is on the upswing, the industry may not be realizing its full potential. Early recordings were unique in that they relied on physical 
space, innovation, and experimentation to achieve many of the sonic textures that created the sound. Two such examples, as discussed by Théberge (2004), are Capitol Records' reverberation chambers and RCA Victor New York's dedication of studio space for an echo chamber. These facilities represent a handful of quintessential spaces that were key to many successful recordings. As the industry has matured over time, recording technology has advanced significantly, becoming more affordable and leading to the growth of smaller project studios (Pras, Guastavino, and Lavoie 2013). Resembling somewhat of an inverse relationship, even though the affordability and availability of technology has increased, originality and innovation has decreased. An industry that was built using experimental processes, physical technology, and space has been replaced by readily available, perhaps even commodified plug-ins rampant with presets and artificial creativity.

Such substitution, driven in part by the economic realities of the music industry (Pras, Guastavino, and Lavoie 2013) has resulted in recordings that employ the use of expected or standard equipment and plug-in resources by modern engineers who, arguably, lack a deeper understanding of the analog and more organic processes that were the basis for the development and creation of today's modern studio technologies. Though accessibility to diverse musical content has increased with the propagation of digital music and the internet, recording technology and techniques have homogenized to the point that recordings risk being labeled as predictable, formulaic, or outright boring. Furthermore, the role of the engineer - a role well-positioned to transform from that of a technician to a sonic intermediary who captures and presents the complex cultural relationship between sound, people, and place - has been reduced to a button-pushing, mouse-clicking role focused on technical precision and software mastery.

Advances and changes in music distribution have altered the way consumers receive and subsequently value music, as lossy, lower-quality recordings become the norm for the consumer (Pras, Guastavino, and Lavoie 2013; Watson 2016). Such acceptance by the consumer has trickled back to the studios and labels, resulting in either the redefining of the role and importance of the recording studio, equipment, and approaches, or the closing of studios all together (Théberge, The network studio: Historical and technological paths to a new ideal in music making. 2004). Sans a discerning and articulate consumer who values quality over quantity, the industry needs to bolster its perceived value to fend off other attention-competing media. One way is to change the way that those involved in the music industry approach and embrace their roles, starting with early career sound engineers in post-secondary environments and continuing through professional development opportunities for seasoned sound engineers.

Changing the way industry personnel approach their purpose can result in another way the industry can add valueby creating innovative recordings that engage and challenge the listener. Early on, whether a result of early technological adoption or the youthfulness of the industry, sound engineers did more than transduce acoustic waves into electrical signal fixed in medium - they experimented. Throughout the recording process, they challenged, embraced, and respected technology and aesthetics. Look no further for such evidence than recordings such as When the Levee Breaks (Led Zeppelin 1971) and its explosive drum sound, which was achieved during location recording at Headley Grange (Liu-Rosenbaum 2012); or The Bristol Sessions and the use of ordinary commercial space as temporary studios (Russell 2007) without concern for perfect acoustics; or the earliest rock and roll recordings from the Graves Brothers and the Mississippi Juke Band which were recorded at Hotel Hattiesburg in 1936 (Morris 2014); or any one of a myriad of recordings that came from Nashville's RCA Studio $B$ or London's EMI Studios - Abbey Road, each with their own signature studio sound. In the end, recordings such as these were not just products of the musicians. They were, as Gibson (2005) states, “.... an emotive performance produced in particular spaces and through affective relations between musicians, producers, engineers and technologies" (p. 192).

Fundamentally, the purpose of this paper is to reconsider the role of the sound engineer from a critical cultural perspective. If sound engineers approach their role from a multidisciplinary and critical perspective, sound recordings will be culturally relevant and interesting again, and the significance of the sound engineer's role will increase, cementing the need for qualified sound engineers for decades to come. The burden is not just the responsibility of the sound engineer, but must also be shared by those who work in post-secondary sound engineering education programs. To achieve this, the author first discusses the typical recording process and personnel roles, and then examines the alternative and less mainstream contributions of John Cage, R. Murray Schafer, and Alan Lomax, as they relate to the field of sound recording. From this, a revised approach to sound engineering is proposed using a model that considers the environment, location, and interplay of aesthetics as key components to making recordings and productions sonically interesting and culturally significant. Through a series of tenets, the author further describes how the proposed framework can be integrated into the sound engineer's recording process. Finally, a discussion takes places where positions are redefined in the context of the proposed framework, and the recognition and subsequent integration of such an approach is addressed. 


\section{The Music Industry and Sound Engineering: Processes and Terminology}

It is important to clarify the context in which this paper is written. Governmental categorizations for careers within the music industry vary, but it is universally recognized that the music industry is a subsector of larger industries: the Media and Content Industry (Leurdijk and Nieuwenhuis 2012) in Europe or the Media and Entertainment Industry in the United States (Select USA 2017). The production of recorded music, which is often associated with sound engineering, is considered an aspect of the music industry, but should not be considered an exclusive career path for a trained sound engineer. Within the larger industries, sectors such as theater, television, film, radio, and sound-based art and installations, have similar career opportunities that are rooted in the fundamentals of sound engineering, though often further specialized and referred to using different industry-specific titles. The sound engineer remains the focus of this paper and is discussed often from the musical context, but it should not be assumed that their role is limited strictly to the music industry. From an educational perspective, the fundamentals of sound engineering and recording often begin from a broad sound theory perspective, with specialization coming later in the educational program or even post-graduation. With this said, the author contends that the influence of critical sound culture and theory, along with the forthcoming model, be introduced early and emphasized throughout an educational program. A subsequent discussion will attempt to clarify and differentiate between frequently used terms and positions related to the role of the sound engineer that are often misinterpreted as being interchangeable: audio engineering, recording engineering, sound engineering, and producing.

The complexity of bringing a song to market varies greatly depending on the "level" of the artist. Their market success depends on whether they are an independent musician in control of their own works or a major-label artist signed and committed to deals that involve corporate oversight of their product. The role of the label will also vary depending on the artist and their needs. In some cases, the label will act more like a financial backer, but how involved the label is and how much freedom the artist has depends on the positioning of the artist at the time of signing. In the case of Ed Sheeran, his following and business acumen were established at the time he signed with Atlantic/Asylum records, which gave him more freedom as an artist (Lindvall 2012). From independent to major-label artists, the number of people involved in the recording process depends on the budget or preferences of the talent. At the most basic level, a typical recording session involves the talent and the sound engineer. A producer or manager may be involved too, if the artist so chooses and has the budget. In the case of a major-label artist, the creation and recording of a song can involve numerous writers, beat makers, managers, and engineers, as was the case with the production of Rihanna's Man Down (2010) (Chace 2011). After the initial recording session, the music is mixed and mastered prior to being released. In each of the steps, the personnel involved in the production of the song or album can change.

Regardless of whether the artist is signed, affiliated with a label, or independent, there are several potential positions that may contribute to the production process. Audio engineering and recording engineering are two terms that are inaccurately considered synonymous among those unfamiliar with, or new to, the recording industry. Audio engineering and audio engineer are terms associated with the signal, electrical waveform, or representation of sound (Connelly 2012). Though audio engineering is possible, it is indicative of the manipulation of electronics and should be reserved for those who work with the design of equipment and signal processing.

The Recording Academy (2017) describes another role, the recording engineer, as the "Same as the Engineer, except this person is not necessarily involved in final mixing" ( $p$. 1) (the definition of the engineer, according to the Recording Academy, follows). Berklee College of Music (2017) describes the responsibilities of the recording engineer as one who "operates the mixing console and other equipment during the process of recording music or sound. Recording engineers generally run recording sessions, with oversight from the producer..." (p. 1). Without delving too far into this debate, it is contended that the Recording Academy should further clarify its definition of the recording engineer. For the purpose of this paper, the recording engineer is a technical position focused on the interplay of the electronics and equipment in the recording process.

More accurate and relevant to the recording industry and related fields, as well as being the central focus of this paper, is sound engineering and producing, known by their professional positions as the sound engineer (sometimes just engineer - see below) and the producer, respectively. In their study, Pras and Guastavino (2011) describe the sound engineer position as having "technical responsibility" (p. 74) and find that in addition to the technical skills, musicians expect sound engineers to be concerned with the aesthetics of the session environment and the overall recording as well. The Recording Academy (2017) does not currently recognize the sound engineer as a Grammy-eligible position, but instead, acknowledge the position of engineer: "...the primary person or persons actively responsible for the process of recording and/or mixing a project as well as technical issues and decisions. He or she operates (or oversees the operation of) the equipment during the recording process and makes creative and aesthetic choices in collaboration with 
the artist and producer in order to realize the sounds and concepts envisioned for the project" (p. 1). This aligns with other definitions for sound engineers, and therefore one can extrapolate that the addition of sound in front of engineer is a descriptor intended to provide clarification as to what the engineering is referencing. The author posits that the term sound engineer is applicable to the music industry yet is a baseline term for anyone involved in the engineering of sound, regardless of industry. For the sake of specificity and in keeping with the theory and framework of this paper, sound engineer is used throughout this paper in reference to anyone who engineers sound, music, or otherwise, and the author suggests that related industries recognize the clarification of the position.

By definition, the producer actively oversees the creative and technical aspects of the entire project and the individual sessions (Recording Academy 2017). On producing, Sir George Martin states: "put simply, my job was to make sure recordings were artistically exceptional and commercially appealing, maximizing the qualities of artists and songs" (Myers 2012, 1). Historically, producers were not part of the recording process, and when their role became a defined position, those who took it on were often from the ranks of sound engineers (Jones 2003). It is not surprising that the distinction between the two positions is blurred, with the producer taking on many of the roles of the sound engineer and vice versa, depending on the budget of the artist (Pras and Guastavino 2011). In today's market, it is unlikely that smaller projects will have the budget or need for a separate producer, with the sound engineer taking on all, or some, of the responsibilities of the producer. In the case of the latter, production credit is often shared with the artist or member of their team. The specific roles of the sound engineer and producer, as composited through the works of influential sound scholars, will be revisited and redefined in a subsequent section.

\section{A Breath of Fresh Air}

The ability to record and deliver sound digitally changed the industry, both for the good and the bad. Though compact disc (CD) sales continue to slide (Sanchez 2017) and its resolution is limited, in terms of quality, the CD is the best physical medium available for the mass delivery of album-based music from a portability perspective. Other digital media, including streaming and downloads, provide for even greater portability but often at the cost of quality. Still, digital audio represents a unique recording format as it is the only one that can truly reproduce pure silence, where silence is truly absent of any sort of noise (Kostelanetz and Cage 1987).

As digital technology has advanced over the years, process-oriented creativity and "capturing the moment" has gone by the wayside. Affordable features such as virtual tracks, cheap memory, plug-ins, beat and pitch correction, to name a few, have taken priority and defined the limits of creativity. The problem with the technology is that if everyone has access to it, there is little that sets sound engineers apart from one another. In the days of analog recording, where limitless digital reverberation algorithms and microphone modeling did not exist, the uniqueness of a recording was defined through the interplay of the sound engineer's abilities and skills, the analog equipment, and most of all, the environment.

The environment was a significant element that defined a recording's "sound" and could not be easily duplicated. For example, the sonic environment of the tracking room at Sound City Studios in Los Angeles, especially with regard to the drum sound, was oftentimes the reason bands chose to track at the studio (Grohl 2013). Interestingly, though, the room was never designed to be a great sounding room. "That room shouldn't, on paper, be a great drum room because it's like a big ol' square room" (Jim Keltner in Grohl 2013). It was with a stroke of luck and some quality sound engineering work that the drum sound in the tracking room at Sound City would become legendary. "Every room has their sweet spot for that sound, you know, this I think has always been Sound City's sweet spot" (Grohl 2013).

Recordings today seem to be lacking the luster they once had. For example, the sonic creativity and unique mixing techniques of Sgt. Pepper's Lonely Hearts Club Band (1967) employs mixing techniques that are not readily present in the modern music industry (The Beatles 1967). The sonic qualities and localization of specific instruments in the mix were a result, in part, of technological limitations of the era. Even the more modern studio recording of Pink Floyd's concept album The Wall (Pink Floyd 1979) represents a combination of creative production techniques and the integration of sound effects and location recordings (Povey 2010) that helped differentiate the album from others.

Experimentation was not exclusive to professional recordings. Early on in my career and to this day, I employ analog processes to create specific sounds or textures. For example, the creation of a lo-fi recording through a speaker was actually created by running audio through a lo-fi speaker and re-recording it. During a tracking session, the reverb plugin was not aesthetically adequate, so I moved the singer to a hallway and recorded the natural reverb. When I needed a specific sound from a room, it would be tracked on location. Plug-ins today approximate the sounds and textures I sought back then, but the process itself is an integral part of the recording. Leaving the comfort and confines of the studio results in sonic textures and interactions that are not possible by simply remaining within it. The unique sounds are representative of more than just the artist's music. They 
contain cultural information as a result of the interaction between people, place, and sound, which are specific to the environments in which they were recorded at that time. For such an approach to be integrated and accepted as part of mainstream media today, it requires that the sound projects demonstrate sonic value that a studio cannot create on its own and that the listener can appreciate and connect with. This also necessitates for sound engineers to be skilled and diversified in their craft, and for the artists, sound engineers, producers, labels, and others involved to be willing to relinquish control and be open to the unfamiliar.

Several recordings from $\mathrm{La}$ Blogothèque, a project dedicated to "take away shows," (La Blogothèque 2011) begin to embrace such an approach and act as an inspiration to what music recordings could sound like. Though the project is positioned as an improvised music video capturing a variety of artists performing songs in different locations (Thompson 2008), the sound recordings are raw, embracing interaction between the natural acoustics of the locations, the musicians, and technological or performance limitations. The recordings are a rich sonic experience unlike the studio versions of the songs, but what would become of the recordings if filming was not a priority? Could the recordings highlight the interaction between the song, environment, and culture even more? Selected works, contributions, and theoretical approaches of three influential scholars in the field of sound-John Cage, R. Murray Schafer, and Alan Lomax - are discussed as foundations for redefining the role of the sound engineer from a critical cultural perspective.

\section{Chance and Culture: John Cage}

The pioneering works of American composer John Cage helped usher in a new era of compositional approaches. Controversial as he was, his compositions helped established the notions of "avant-garde" and "experimental," with his musical works transforming traditional musical theory into an ecological journey of sound and silence (Marranca 2012). Throughout his lifetime, Cage's abstract thoughts about sound, listening, noise, and perception challenged the status quo. His philosophy was open and indiscriminate, grounded in Eastern religion (Hinduism, Buddhism) and Chinese philosophy, and inspired by writings including the I Ching and Thoreau's Walden (Kandell 2012; Nyman 1999). What set Cage apart from others was his willingness to accept all sounds as sources of music, without bias, thus embracing and bringing to life the environment in which we exist (Kandell 2012, Marranca 2012).

Controversial among traditionalists, Cage's efforts ushered in a new experimental style of music: the avant-garde movement. As part of the new movement, music vocabulary expanded to include key terms such as prepared, silence, noise, indeterminacy, chance, and electroacoustic. Cage composed many pieces throughout his lifetime, but it was from 1939 through the early 1950s that his most relevant works, representative of the avant-garde movement, were created: Imaginary Landscapes Nos. 1-5 (1939-52), Sonatas and Interludes (1946-48), and most famously, 4'33"' (1952) (John Cage Trust 2013).

The aforementioned pieces challenged the public's traditional view and expectation of music, composition, and performance. For example, Sonatas and Interludes was composed for a prepared piano in which the strings and soundboard were altered using a variety of materials such as bolts, screws, rubber, and weather stripping prior to the performance (John Cage Trust 2013). Following his prepared piano piece, Cage experimented with other sounds and techniques, incorporating indeterminacy and chance into his works. To Cage, indeterminacy was truly an element of the unknown whereas chance operations, oftentimes calculated using the I Ching method, operated within a set of universal knowns (Kostelanetz and Cage 1987). Used interchangeably at times, there is a difference between chance and indeterminacy. The former is more of a technique used when composing a piece whereas the latter occurs during the performance of a piece (Dickinson 2007) where "you are to supply the determination of certain things that the composer has not determined." (Kostelanetz and Cage 1987, 116). To elaborate, Imaginary Landscapes represents indeterminacy. The pieces in the series rely on a series of unknowns, as in the case of Imaginary Landscape No. 4 where performers adjust the volume and frequency knobs of an analog AM radio according to the composition. The indeterminacy is present because the piece can never be performed the exact same way twice nor will it sound the same due to the temporal nature of radio broadcasts.

Cage's most famous piece, 4'33', defined his career and transformed him from novice to expert in the experimental, avant-garde genre. Known as the silent piece, or Silent Prayer (Marranca 2012), 4'33" further elaborated on the concepts of experimental music and indeterminacy. Originally performed using piano, the piece is indeterminate in two ways: First, the number and instruments of musicians is unspecified and second, the three movements are essentially movements of time-defined silence. During the silence, the ignored, unintended sounds of the environment become the pages of written notes (Kandell 2012). The piece created controversy when it was first performed, but Cage's point was that silence, or the absence of expected sound, is not silence at all. In Cage's words, "silence also is not silent - it is full of activity" (Kostelanetz and Cage 1987, 121). Using silence in a piece designates a zero starting point, opening the piece up to the unintentional, which allows the listener to listen as they choose without having anything forced 
upon them (Kostelanetz and Cage 1987). It is within the framework of non-intention, indeterminacy, and chance that the value of Cage's contributions to sound and music are realized and have the ability to impact the future of the music industry and sound engineers.

It is no secret that Cage did not care for recordings of his compositions (Tone 2003, Haskins 2012), given that recording his work contradicts the tenets of the avant-garde movement to which he spent his lifetime promoting. Throughout the numerous interviews available, Cage emphasizes the importance of the performance over the playback of a recording as a substitute (Tone 2003) because “...recordings...turn music into an object, and music is actually a process that's never twice the same" (Kostelanetz and Cage 1987, 128). Towards the end of his career, Cage did recognize a value in recording works for documentary purpose or for intentional and specific performance (Grubbs 2014; Tone 2003), but never considered the potential cultural value of "silence" or "indeterminacy" in the recordings themselves. In addition, due to his unexpected death in 1992, Cage never had the opportunity to experience his own composition for CD (Swed 1995), nor was he able to consider how mobile performance spaces associated with the playback of a recording (i.e., in the car, home, bus, train station, etc.) represent a different perspective of indeterminacy and chance, brought upon by the listener, the location, and the moment in which the playback and listening interaction is taking place. This concept will be further addressed as part of the framework for future sound engineers and recordings.

\section{Preserving the Sonic Landscape: R. Murray Schafer}

R. Murray Schafer's contribution to the field of sound expands upon themes introduced by Cage, notably the presence of environmental sounds as part of our acoustic environment. As the "Father of Acoustic Ecology," Schafer is best known for the World Soundscape Project, which was developed during the 1960s while at Simon Fraser University, and was dedicated to "the study of the relationship between people and their total acoustic environment" (Hoshowsky 1997, 12). The World Soundscape Project was pivotal in bringing attention to the idea that natural sounds that surround us can be part of a musical composition (Wrightson n.d.). As a result of his involvement in the project, Schafer essentially cemented his position as an avant-garde composer whose musical works not only included the environment in part, but also relied on it to be a foundation for compositions, as exemplified through Music for Wilderness Lake (Ward 2009).

Schafer is credited with introducing the concept of the soundscape (Samuels et al. 2010), leading to the creation of the field of acoustic ecology. Though the complete history and complexity of the soundscape is beyond the scope of this paper, two concepts are relevant to the future of recording arts: listening and schizophonia. Listening is a complex term, and in the context of soundscapes and acoustic ecology, differentiation is made between background and foreground listening. A parallel is oft drawn between landscapes and soundscapes. Soundscapes, like landscapes, convey cultural information. "As landscape is constituted by cultural histories, ideologies, and practices of seeing, soundscape implicates listening as a cultural practice" (Samuels et al. 2010, 330). Listening, in the context of soundscapes, is much more complex than the passive listening - or hearing - that consumes most of our day. Similar to how a landscape has foreground and background objects, listening is comprised of foreground and background sounds, keynotes, sound signals, or even soundmarks (Truax 1999; Truax 2001).

Classifying a sound as foreground or background is not related to the physical proximity of the sound. Rather, a sound is considered foreground or background based on its prominence during the listening process (Truax 2001). Sounds that are usual parts of the acoustic environment are background sounds. Sounds that stand out in an environment, or sound signals, are part of the ambient environment, and those which occur frequently are considered keynotes-a concept similar to music where "the key of the piece is its fundamental tonality" (Truax 2001, 25). Conversely, foreground sounds are those that stand out in the listening environment. If the sound is to be listened to, it is considered a sound signal, and if the sound is unique enough to the location that it is unlikely to be found elsewhere, it could even be a soundmark - a sound that represents cultural and historical importance and should be preserved (Truax 1999).

As much as Cage was not a fan of recordings as a substitute for the actual performance, Schafer was not a fan of splitting sounds from their sources because it was unnatural in that it temporally and spatially shifted sounds out of their original context (Samuels et al. 2010), creating distance between the listener and the source (Kelman 2010) resulting in unrealistic listening experiences. Schafer referred to this phenomena as schizophonia. With the ability to record, sounds that were once limited to a specific time or place could now occur anywhere at any time, creating a soundscape where recorded sounds become part of the background and contribute to underlying indiscriminate noise, thus transforming a sonic environment into a low-quality, or lo-fi, listening environment (Schafer 1993; Truax 1999) built upon unnatural sonic experiences.

Schafer's concern for recorded, "schizophonic sound" does not mean that soundscapes should not be recorded. In fact, through the World Soundscape Project, there were several instances where recordings were made of natural envi- 
ronments. What Schafer strives to convey is that breaking a sound apart from its natural environment and placing it in an unnatural environment can create schizophonia and thus, care should be taken with the recording and presentation of a soundscape. Ideally, soundscapes would consistently be of high fidelity, or hi-fi: a classification of a listening environment whereby sounds are heard clearly and the listener does not have to fight to hear the detail or orientation of the soundscape (Truax 2001).

From a sociological perspective, recording environments is not new. The recording of places and environments has been an integral part to documenting and archiving cultures vis-à-vis ethnographic or musicological research methods. However, it is important to note that the value of a soundscape, with regard to what is or what is not recorded, relies on the decisions made by the recordists and the historical information upon which such decisions are made (Samuels et al. 2010). To the sound engineer, this means that the decisions to record or not record sounds should be well planned and carefully considered.

\section{The Culture of Music: Alan Lomax}

While John Cage and R. Murray Schafer's contributions to the field of sound were primarily from a compositional approach, Alan Lomax's work was a result of documenting culture as a musicologist. His work was inspired by his father, John Lomax, whose desire was to preserve America's traditional music (Carlson 2014). His passion resulted in the discovery of several musicians and one of the largest collections of folk recordings (Association for Cultural Equality 2013; Rose 2012).

As an academician in the field of ethnomusicology, Alan Lomax recognized the different approaches to studying the culture of music early on. Of particular interest to him was the role of music in a social context. Through decades of research, he postulated that a connection between emotion and music exists, and theorized that consistent musical styles within a culture are indicative of specific needs or drives (Lomax 1962). Lomax's examination of music in cultures and the subsequent coding (cantometrics) of the music supported his position that music represents specific cultural and social structures.

The contribution of Lomax to the field of music is rarely discussed from the perspective of the sound engineer. As impressive as it is, Lomax's collection of over 17,000 recordings of false takes, music, and interviews (Rose 2012) were heralded for their content, not for their technological feat. Though field-based recordings were impressive at the time, Lomax was not the first, nor a pioneer in the field. Labels from across the country were conducting location-based recording sessions as early as 1923 (Russell 2007). The difference between the Lomax recordings, of which most cur- rently reside in the Library of Congress, and the early field recordings from the $1920 \mathrm{~s}$, is the cultural significance of the Lomax recordings. His recordings were of such value that he was offered, and subsequently accepted, a position at the Library of Congress in 1936 and took his music and interviews to the airwaves as a radio host throughout the $1930 \mathrm{~s}$ and 1940s (Donaldson 2013).

Lomax has been generally revered as "the man who recorded the world" (Szwed 2010), but he has also come under scrutiny. During the 1950s, he was subject to FBI surveillance and even asked to sign a statement that he had never been a member of the Communist Party (Szwed 2010). One of Lomax's pivotal works, Mister Jelly Roll (1950), was the subject of criticism in recent literature. In comparing the interaction and accounts as written by Lomax with the recently released complete interviews, Martin (2013) suggests that Lomax "frequently imposes his own schema" (30), and "Because of his [Lomax's] romantic conceptions of folk culture, Lomax is compelled to attribute to Morton his own preoccupations, to adjust Morton's story to fit his own a priori model of authenticity..." (Martin 2013, 32).

Whether Lomax's work continues to be scrutinized in the future or not, he should be recognized as one of several scholars of the time whose contributions helped shape the field of musicology and, indirectly, the field of sound. Additionally, his relevance to this paper resides in the fact that he used field recording - an extensive amount for that time period - to examine the role of music and culture. At a minimum, his work demonstrates that music offers cultural information if recorded and investigated appropriately. If you consider Lomax's work and transfer the fundamentals of ethnographical research to sound engineering, the sound engineer's role is well positioned to assimilate the functions of an ethnographer. But this only becomes feasible if their education supports such positioning and if their access to and recording of musicians and performances results in the extrapolation of culturally significant information. This is only possible if the sound engineer is trained properly, empowered as a significant contributor through their role in the production process, and if they make decisions in an educated and thoughtful manner.

\section{A New Model and Approach for the Sound Engineer}

The disruption the industry experienced in the early 2000 s came as a result of a perfect storm between 1) technological advancements in both recording technology and distribution channels and 2) changing economics as technology became more accessible and affordable, resulting in both studios and artists detaching themselves from labels in favor of an independent model. The changes had a significant impact on the industry, from which it is still feeling the ef- 
fects today in the form of declining album sales and revenue (Crompton 2014, Sanchez 2017). Studios were closing, and those that decided to hold on had to redefine their purpose and target market. If similar digital technology that was in the studios was available to musicians for about the cost of tracking an album, the need for the studio is diminished. In response, the studios redefined their role as experts in the field of perfect production, which would take place in great sounding, acoustically controlled studio environments, with access to the latest technology and, in many cases, vintage equipment.

As the tumultuous times normalize, the formulaic and commercial-centric approach to recording and producing music is evident. The state of the recording industry and recent encounters with productions that embrace natural environments reignited an interest that began nearly twenty years ago when I began working with musicians: tracking in natural environments as a means to capturing a performance that represents and conveys the culture of the recording through the interaction between the artist, the environment, and the music. But tracking in a natural environment cannot be haphazard or lacking quality if it is to make a case for permanency in the musical library of consumers. This requires that the engineer - the sound engineer-play a highly defined role in the production of music and, from a critical perspective, consider the artistic and philosophical value of John Cage, R. Murray Schafer, and Alan Lomax, in tandem.

Such approach for the sound engineer can offer an aesthetic fortitude that parallels the intensity of a Tonmeister - the European term for someone who has extensive education in music and technology (Borwick 1973) and is a graduate of a certified Tonmeister program (Recording Academy 2017). Lomax (1962) recognized that music can have more to offer beyond just musicality and suggested that even a field as focused on music as ethnomusicology "should turn aside, for a time, from the study of music in purely musical terms to a study of music in context, as a form of human behavior" (425). This can be accomplished by requiring a basic knowledge of acoustics in varied environments, promoting technological competency in both form and function across media, and ingraining an understanding of person-placesound interaction from a multidisciplinary perspective rooted in the social sciences (i.e., sociology, anthropology, media, and psychology), the humanities (i.e., arts, music, literature), and even the hard sciences (i.e., math, physics, and engineering).

Figure 1 represents the conceptual model for how the contributions of Cage, Schafer, and Lomax can be applied to influence the sound engineer's role and approach in the recording of music. Note, however, that mixing is not specified in this model, though it is feasible, if not recommended, that the "sound mixing engineer" be the same, affiliated, or an informed person who is familiar with the production so as to maintain consistency and integrity in the work.

Cage's concepts of indeterminacy and silence, Schafer's work involving silence, the soundscape, and culture, and Lomax's research into cultural representations and music, along with his field recording techniques, have led to the development of the aforementioned model and approach for sound engineers in the recording industry. It should be noted that the approach is not intended to be universal; certain genres of music or production outcomes (i.e., to create commercial background music, royalty-free catalog music, or other commercially-driven production) may not be appropriate for such an approach. As sound engineers consider the impact, the tenets set forth below provide additional clarification to the construct.

Sound engineers should understand the purpose or goal of the recording. This is not saying that sound engineers do not understand the purpose, but rather, that they should look beyond the contracted task for an opportunity to transform a recording into something more. To Lomax, the purpose of recording was to document the music and inherent culture present in music and communication. Though Cage and Schafer questioned the value of recordings, they recognized that music recording will continue, regardless of whether "live" performances or specific locations are available. In the music industry, it is necessary to understand the purpose of the recording, which may or may not include the opinions or directives of others, such as a label or manager. It is okay to not approach every recording as though it has cultural value. Some music, based in its intention, will have little cultural information or value embedded as a result of its purpose. A sound engineer is still fully capable of capturing the best sounds or performances in a studio for such a project, but they should be cautious as to not fall into the "studio" habit.

Silence is just as important as the music itself. Cage and Schafer promoted the value of silence, going so far as to consider it a musical element. But what is more important here is that silence is a completely subjective concept with no shared definition or meaning. This means that while architects and engineers spend hundreds of hours trying to figure out how to create a "quiet" recording studio, it is not necessary for all recordings. If a sound engineer, in consultation with the artist, decides that a room with a louder ambient noise floor or a specific type of reverberation is the best fit to extract an emotional performance that enhances the cultural aspect of the music, place, or time, then it should be used. Do not dismiss silence, or noise for that matter, as unharmonious. Of course, this is not suggesting that extremes be ignored; for example, attempting to record a blues song on a freight train traveling at 60 miles per hour 


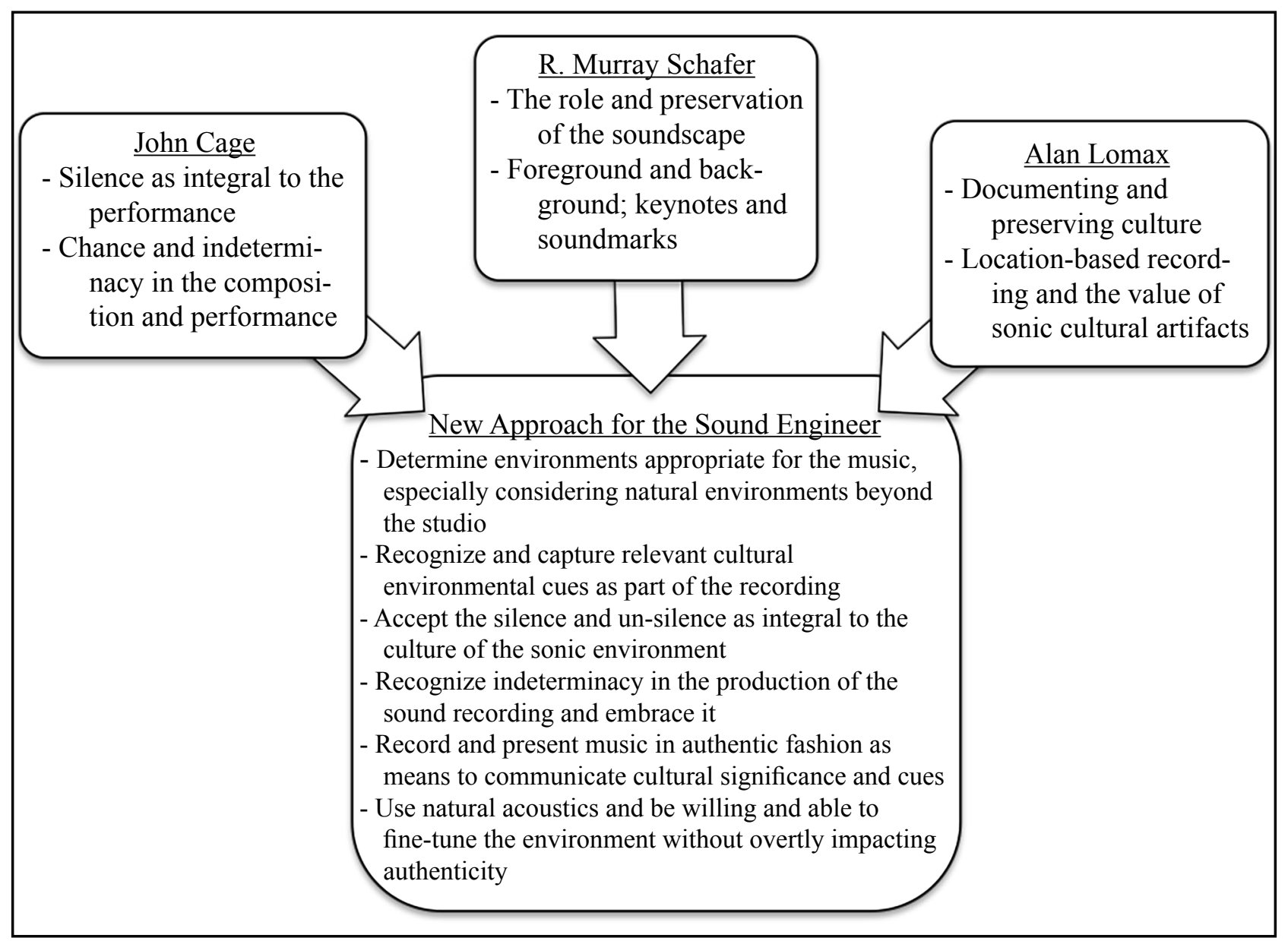

Figure 1. The contributions and influences of Cage, Schafer, and Lomax towards redefining and expanding the role of the sound engineer.

would not be feasible.

Sound engineers should not dismiss sonic environments and cues. If there is one key concept to extrapolate from Schafer it is the informative value of all sonic environments - the soundscape itself. Excluding live concert recordings, sound engineers have been led to believe that the studio is the only place to record a quality song or album, but similar to the previous point, our sonic environments and the musicians themselves present significant opportunity and surprise if they are explored: building may be a café by day, but a great recording environment at night, or perhaps an old Vox factory that was later transformed into an iconic tracking room known for its drum sound years later (as was the case with Sound City Studios).

Indeterminacy I: Culture and the unknown in the recording can enhance the final product. The sonic environment can be impacted by the unknown or unexpected, such as a door opening, street traffic going by, or pedestrian observers interacting with the environment. Similarly, indeterminacy occurs in the recording of the music vis-à-vis the musician's choice of tempo, emotion, sound texture, et cetera - all of which are relevant to the understanding of culture. The re- cording process does not need to be solely about perfection; musicians can make mistakes or deviate from their plan. The same can be said of the recording process and the capturing of "live" recordings. Cage did not believe in substituting live recordings for the real experience because the technology represented impossible feats. Likewise, overdub after overdub and layer upon layer of tracks can misrepresent the meaning and message. If the instrumentation cannot be recorded live or near-live or if it can, but requires an extensive rearrangement of the environment or sonic space, the sound engineer should consider whether it is worth recording.

Indeterminacy II: The collision of environments. The second way indeterminacy impacts the recording is upon playback. When approaching the recording process from this perspective, the environment in which the music is being recorded is one environment to consider, but the playback environment represents a secondary environment (studio for mixing or the consumer's environment). Therefore, it is necessary to recognize that certain indeterminate sounds and environmental cues may be optimal for binaural listening (headphones), but may not be ideal for playback on speakers in an environment that is not designed for listen- 
ing such as a car, a reverberant room in a house, or a space where the listener is not properly positioned in the listening field. One of the advantages of this redefined sound engineering approach is that it is introducing listeners to rich sonic environments at a time when the ubiquity of earbuds (ever present throughout one's day) are slowly isolating and detaching the individual from the beauty of their sonic environment.

Appreciate technology and determine its appropriate role in recording. Technology presents tremendous opportunity in the field of recording. Unlike Lomax, who traveled around with a cylinder recorder (resulting in less-than-optimal recordings by today's standards), quality recording technology sounds remarkably better, has virtually no noise floor, is easily mobile, and has become more affordable. But the technology cannot and should not replace analog thought or a critical perspective. Seeking natural effects or unique tonal qualities can add important cultural information and artifacts to the performance and recording. The apt sound engineer should employ the use of plug-ins and digital processing using a thoughtful approach. Also, sound engineers need to consider the environment in which they are recording and any technological opportunities or limitations imposed by the environment, the subject being recorded, or as a result of the two interacting. It may mean choosing a different song or using different instrumentation, such as an acoustic guitar rather than an electric. The sound engineer must consider the desired outcome and analyze how the convergence of the many pieces will impact the final recording. The last thing a culturally apt sound engineer should do is pollute the environment-either sonically or otherwise.

Being a sound engineer is more than technical precision. Critical and active listening is a must for sound engineers, but so is having a penchant for finding, experimenting, listening, questioning, learning, and studying. All too often, when an engineer finds a specific sound or technique in a studio they hold on to it and use it repeatedly. The end result is artist after artist sounding more like the sound engineer's technique rather than their own musical or stylistic identity. There are several instances where a specific technique was used on different artists but resulted in such a similar sound, impacting the sonic and musical identities of the artist. When a client hires a sound engineer, the sound engineer should advocate for letting the music, environment, and interaction determine the initial sonic form of the recording, followed by informed and meticulous shaping of the sound to achieve a unique sonic work.

Embrace the holistic role of the sound engineer. Sound engineering should be approached from a multidisciplinary cultural perspective that involves music, technology, math, engineering, media, science, sociology, psychology, and art.
The newly redefined role of the sound engineer carries substantial responsibility for ensuring the accurate delivery of the message from the sender (musician) to the receiver (consumer). Similar to how film companies scout locations for a movie before production, sound engineers should explore environments in search of the best fit, given their knowledge of the music, project outcomes, context, and influences of the musician. Just as a writer experiences writer's block, a sound engineer may experience soundblock - an inability to move forward in a sound production. They need to be willing to move beyond their comfort zone, try something new, or take a breather as needed.

\section{Discussion}

When the framework for this paper began to take shape, it was thought that the role of the sound engineer, and sound engineering as a career, had to be reconstructed. But that is not the case. In considering the series of specialist sound roles across a multitude of industries that share the same fundamentals of sound engineering in some form, it became clear that the role of the sound engineer had to be expanded and redefined as a result of advancing technology that has resulted in a form of technological determinism with regard to the perceived value of music and sound as a whole. Towards redefining the role, this cultural approach for the sound engineer should be considered an expansion to the existing role of the sound engineer, which impacts how other roles are defined. The discussion that follows revisits and refines previously discussed roles that are specific to the music industry, within the context of expanding the role of the sound engineer to include critical cultural principles.

Previously, the roles of audio engineer and recording engineer were introduced. These titles are often used by novices and those unfamiliar with the entertainment industry to describe what is usually a role that more closely resembles that of the sound engineer. The audio engineer is a technical position on the development and design side, and is defined as a person who manipulates the electronic form of sound, the audio, at the electronics level-essentially an electrical engineer with a specialty in audio. The Academy's definition for the recording engineer, discussed previously, falls short of acceptable as it merely differentiates the recording engineer from the head (sound) engineer as someone who is not involved in the mixing. Such minimal differentiation projects an inappropriate simplicity to the recording process. It assumes that the mixing process and recording process are independent of one another and ignores the notion that approaches used in the recording process become the foundation for future mixes. Rather, it is more appropriate that the recording engineer be defined as someone who is proficient at the technical operations of sound/audio equipment who operates under the direction of a head sound en- 
gineer or producer.

Historically, the engineer's role has been essential in the production process, but "sound" was absent from the title. It remains the contention of the author that all things involving sound in the entertainment industry are born out of the fundamental theories related to sound engineering. Additionally, the Recording Academy should expand its definition of engineer to sound engineer to better represent the complex responsibilities and expand the role of an already undervalued position. With a keen ear for aural aesthetics, a critical cultural perspective, an expertise in the use and application of diverse recording technology and processes, and a deep, organic sense for engineering sound from multiple perspectives, the sound engineer is responsible for shaping sound across all types of sound projects - from traditional music recording to mixing for picture, to short and long form radio production and sound art. A true sound engineer, therefore, is a sonic agnostic when it comes to the industry in which the sound work exists. Considering the history and importance of the sound engineer to the music industry, the sound engineer must be able to discern project outcomes and determine the best approach for the recording project and is responsible for using their knowledge to record and shape sound with or without structural, musical, or performance influence, towards capturing a "best" performance rich with texture and cultural information.

This expanded definition for the sound engineer further challenges the purpose and role of the producer in the music industry. The producer is a role that may or may not be present and can be selected by the musician or business affiliate who has interest in the project, such as a label or manager. Additionally, the producer may be a separate role or part of an existing role. In the latter example, the sound engineer, the artist, or a member of the group can take on the producer role exclusively or collaboratively with other project members. Considering that producers often come from the rank of sound engineers (née engineers), and they have both creative and technical oversight of the entire project, they are the person who develops the artist, shapes the sound, and whose role is embedded into the writing or performance process to the extent that they impact or alter significantly the structure, musical attributes, and/or performance. To some extent, the producer role works behind the scenes as a quasi-member of the talent. One significant consideration, though rare, is that the producer may not be technically proficient in the operations of sound or audio equipment.

As the sound engineer further develops his or her craft using this model, musicians may need to rethink the role of the producer. A well-rounded sound engineer can be just as effective as a producer, and the intellectual input that goes into engineering and shaping sound is just as relevant. Within the traditional framework, the producer manages a project and "forms" or "polishes" a song or artist. As a result, their creative control can be overbearing and result in a product that, similar to the previous suggestion, misrepresents the true sound or intention of the artist in favor of other interests, such as financial or image and marketing.

It is unlikely that the aforementioned changes will be universally accepted by the industry, education, and consumers, but options do exist. To begin, specific marketing steps have to be taken to educate consumers about music and sound. This can present a challenge, but with industry support it is not impossible. Not every recording or sound project will justify an intense aesthetic approach, and consumers need to understand that different musical performances call for different sound recording aesthetics. Not every sound recording needs to be perfect and clear or authentic and raw. Different songs and locations call for different recording techniques. Consumers have already demonstrated that they are open to sonic differences in recordings with the simultaneous existence of lossless and lossy digital formats, compact disc, vinyl, and high-definition audio in the marketplace. One solution to ensuring that critical cultural, aesthetically rich recordings are properly marketed and delineated would be to create a "standards" demarcation, similar to how "Compact Disc" and "Stereo" have been used to convey specific standards, but with the performance and sound engineering approach as the determining factor.

Educating future engineers and existing engineers on the critical cultural approach becomes integral to the future of sound engineering as a field. Minimally, sound engineering programs should offer one or two intensive critical sound studies courses that introduce critical perspectives and their application to sound projects. Potential for a designated specialization or certification also exists, for those programs that want to exceed minimum standards and focus on a more intense approach. This type of framework mirrors other specialty designations, such as the Tonmeiseter designation, which is granted based on completion of a recognized Tonmeister training program. It would be prudent for both industry and education sectors to recognize the cultural specialty and develop a designation for sound engineers who undergo additional training in culture and aesthetics. This of course begs the question: how would such a designation be verified and managed? One suggestion would be to utilize current educational organizations such as the Music and Entertainment Industry Educators Association (MEIEA), the Broadcast Education Association's (BEA) Radio and Audio Media division, the World Forum for Acoustic Ecology (WFAE), or the Recording Academy to establish and recognize such a designation.

\section{Conclusion}

This paper set out to establish a critical cultural model and 
in doing so, redefine the role of the sound engineer. Sound engineers who adopt such an approach have the potential to create aesthetically and culturally rich recordings that reinvigorate the industry, the listening experience, and the role itself. This approach should not be construed as a universal standard or style. Rather, the sound engineer - either on his or her own accord or in consult with the client - captures and shapes sound to present the best possible production given the desired outcomes and project potential. The need for redefining the sound engineer's role to include a critical cultural, multidisciplinary understanding of person-placesound interaction is necessary towards elevating the role of the sound engineer, and should be an optional path or endorsement in sound education programs. The sound engineer is the connection between artist and consumer, and can have significant influence in how the message is perceived. The sound engineer's role must be considered the starting point to transforming the consumer's perceived value of sound recordings from commodity to cultural signifier.

For many reasons, commercial recordings have become formulaic, but to no fault of their own: consumers have not been discriminate listeners, live shows have taken priority over recordings, and album sales have declined due to economic challenges and consumer preferences. However, if selected recordings become relevant, substantial, and unique, it is believed - as evidenced by niche markets such as La Blogotheque and underground recordings - that consumers will embrace sound recordings as more than just entertainment.

Cage, Schafer, and Lomax, as a collective, have never been considered for their potential influence on the recording process. Their works were considered avant-garde for their time, or had limited commercial value due to technological constraints and lacking consumer awareness. But in today's era, where location and mobility has minimal impact on technology, there is no reason for a sound engineer to stand idly by in a studio while sonic environments, rich with aesthetic value, await the opportunity to interact with a recording project, creating a culturally significant and meaningful sonic masterpiece. This new breed of sound engineers will be able to reshape an industry marred by monotony, homogeneity, and lack of innovation.

In closing, as sound recording continues to take place, and as listeners are inundated with a plethora of listening options, it is essential for musicians and sound engineers to bring relevance to their music and sound recordings, respectively. Perhaps one day, rather than using a studio and instantiating plug-ins to create a non-existent space, a sound engineer will instead find an acoustically and culturally rich place - one where the musician can feel comfortable, connect with the environment, and provide the consumer with the performance of a lifetime.

\section{References}

Association for Cultural Equality. 2013. Alan Lomax. Accessed October 19, 2014. http://www.culturalequity. org/alanlomax/ce alanlomax bio.php.

Beatles, The. 1967. Sgt. Pepper's Lonely Hearts Club Band. Comp. The Beatles.

Berklee College of Music. 2017. Careers in Music Production \& Engineering. Accessed December 28, 2017. http://www.berklee.edu/careers-music-production-and-engineering.

Borwick, John. 1973. "The tonmeister concept." AES Convention 46. AES.

Carlson, Peter. 2014. "Lead Belly wows the Lomaxes." American History 49, no. 4: 20.

Chace, Zoe. 2011. Planet Money: How Much Does It Cost To Make A Hit Song? June 30. Accessed October 17, 2014. http://www.npr.org/blogs/money/2011/07/05/137530847/how-much-does-it-cost-tomake-a-hit-song.

Connelly, David W. 2012. Digital Radio Production, Second Edition. Long Grove: Waveland Press.

Crompton, James. 2014. "IBISWorld Industry Report 51224: Audio Production Studios in the US." IBISWorld. August. Accessed October 16, 2014. www. ibisworld.com.

Dickinson, Peter. 2007. CageTalk: Dialogues with and about John Cage. Rochester: University of Rochester Press.

Donaldson, Rachel C. 2013. "Broadcasting diversity: Alan Lomax and multiculturalism." The Journal of Popular Culture 46, no. 1: 59-78. https://doi.org/10.1111/ jpcu. 12016.

Gibson, Chris. 2005. "Recording Studios: Relational Spaces of Creativity in the City." Built Environment 31, no. 3: 192-207.

2013. Sound City. Directed by Dave Grohl. BBC Worldwide.

Grubbs, David. 2014. Records Ruin the Landscape: John Cage, the Sixties, and Sound Recording. Durham: Duke University Press.

Haskins, Rob. 2012. John Cage. London: Reaktion.

Hoshowsky, Robert. 1997. "Breaking the sound barrier: R. Murray Schafer." Performing Arts \& Entertainment in Canada 31, no. 2: 12.

John Cage Trust. 2013. Database of Works. Accessed October 16, 2014. www.johncage.org.

Jones, Steve. 2003. "Producer." In Continuum Encyclopedia of Popular Music of the World Part 1 - Performance and Production Volume II, by John Shepherd, David Horn, Dave Laing, Paul Oliver and Peter Wicke, 196-197. New York: Continuum. 
Kandell, Leslie. 2012. “John Cage's Centennial: Will they be played at the same time?" American Record Guide 75, no. 3: 7-9.

Kelman, Ari Y. 2010. "Rethinking the Soundscape: A critical genealogy of a key term in sound studies." The Senses \& Society 5, no. 2: 212-234. https://doi.org/10.2 752/174589210X12668381452845.

Kostelanetz, Richard, and John Cage. 1987. "The Aesthetics of John Cage: A Composite Interview.” The Kenyon Review 9, no. 4: 102-130.

La Blogothèque. 2011. HomePage - La Blogothèque. Accessed October 14, 2014. http://en.blogotheque.net/ homepage/.

Led Zeppelin. 1971. "When the Levee Breaks." Untitled.

Leurdijk, Andra, and Ottilie Nieuwenhuis. 2012. Statistical, Ecosystems and Competitiveness Analysis of the Media and Content Industries: The Music Industry. Reference Report, Seville: Joint Research Centre of the European Commission. https://EconPapers.repec. org/RePEc:ipt:iptwpa:jrc69816.

Lindvall, Helienne. 2012. "Behind the music: What do record labels actually do? You'd be surprised." The Guardian - Online, February 2. https://www.theguardian.com/music/musicblog/2012/feb/02/behind-music-record-labels.

Liu-Rosenbaum, Aaron. 2012. "The Meaning In The Mix: Tracing A Sonic Narrative In 'When The Levee Breaks'." Journal on the Art of Record Production 7. https://www.arpjournal.com/asarpwp/the-meaning-inthe-mix-tracing-a-sonic-narrative-in-'when-the-leveebreaks'\%.

Lomax, Alan. 1950. Mister Jelly Roll. New York: Duell Sloan \& Pierce.

Lomax, Alan. 1962. "Song structure and social structure." Ethnology 1, no. 4: 425-451.

Marranca, Bonnie. 2012. “The Mus/Ecology of John Cage." PAJ: A Journal of Performance and Art 34, no. 3: 27-34.

Martin, Katy. 2013. "The preoccupations of Mr. Lomax, inventor of the "Inventor of jazz"." Popular Music and Society 36, no. 1: 30-39. https://doi.org/10.1080/03007 $\underline{766.2011 .613225}$.

Miller, Leta E. 2012. "Henry Cowell and John Cage: Intersections and Influences, 1933-1941." Journal of the American Musicological Society 59, no. 1: 47-111, 234.

Morris, Benjamin. 2014. Hattiesburg, Mississippi: A History of the Hub City. Charleston, South Carolina: The History Press.

Myers, Marc. 2012. "He Had You Hooked on the Beatles." The Wall Street Journal, September 10: 1.
Nettl, Bruno. 2005. The study of ethnomusicology: Thirty-one issues and concepts. Champaign: The University of Illinois Press.

Nicholls, David. 1990. American Experimental Music 1890-1940. New York: Cambridge University Press.

Nielsen Company, The. 2014. "Music 360: Americans make music their top entertainment choice." Nielsen. October 2. Accessed December 26, 2017. http://www. nielsen.com/us/en/insights/news/2014/music-360americans-make-music-their-top-entertainment-choice. html.

—. 2017. Time With Tunes: How Technology is Driving Music Consumption. November 2. Accessed December 26, 2017. http://www.nielsen.com/us/en/insights/ news/2017/time-with-tunes-how-technology-is-driving-music-consumption.html.

Nyman, Michael. 1999. Experimental Music: Cage and beyond. Cambridge: Cambridge University Press.

Pink Floyd. 1979. The Wall. Comp. Pink Floyd.

Povey, Glenn. 2010. Echoes: The Complete History of Pink Floyd. Chicago: Chicago Review Press.

Pras, Amandine, and Catherine Guastavino. 2011. "The role of music producers and sound engineers in the current recording context, as perceived by young professionals." Musicae Scientiae 15, no. 1: 73-95. https:// doi.org/10.1177/1029864910393407.

Pras, Amandine, Catherine Guastavino, and Maryse Lavoie. 2013. "The impact of technological advances on recording studio practices." Journal of the American Society for Information Science and Technology 64, no. 3: 612-626. https://doi.org/10.1002/asi.22840.

Recording Academy. 2017. "Engineer Grammy Award Eligibility Crediting Definitions." Recording Academy. Accessed December 30, 2017. https://www.grammy. $\mathrm{com} / \mathrm{sites} / \mathrm{com} /$ files/pages/engineer_definitions_for awards.pdf.

—. 2017. "Producer Grammy Award Eligibility Crediting Definitions ." Recording Academy. Accessed December 30, 2017. https://www.grammy.com/sites/com/ files/pages/producer definitions for awards.pdf.

Rose, Joel. 2012. The Record: Alan Lomax's massive archive goes online. March 28. Accessed October 19, 2014. http://www.npr.org/blogs/therecord/2012/03/28/148915022/alan-lomaxs-massive-archive-goes-online.

Russell, Tony. 2007. "Country Music on Location: 'Field Recording' before Bristol.” Popular Music 26, no. 1: 23-31. https://doi.org/10.1017/S0261143007001109. 
Samuels, David W., Louise Meintjes, Ana Maria Ochoa, and Thomas Porcello. 2010. "Soundscapes: Toward a Sounded Anthropology." Annual Review of Anthropology 39: 329-345. https://doi.org/10.1146/annurev-anthro-022510-132230.

Sanchez, Daniel. 2017. "Everything You Need to Know About Music Sales in 2017." Digital Music News, July 5. Accessed January 16, 2018. https://www. digitalmusicnews.com/2017/07/05/buzzangle-music-sales-2017/.

Schafer, R. Murray. 1993. The Soundscape: Our Sonic Environment and the Tuning of the World. Rochester: Destiny Books.

Select USA. 2017. Media and Entertainment Spotlight: The Media and Entertainment Industry in the United States. Accessed December 29, 2017. https://www. selectusa.gov/media-entertainment-industry-united-states.

Swed, Mark. 1995. "The Cage Records." Schwann Opus, Winter: 8A-21A.

Szwed, John. 2010. Alan Lomax: The man who recorded the world. New York: Penguin Group.

Théberge, Paul. 2004. "The network studio: Historical and technological paths to a new ideal in music making." Social Studies of Science 34, no. 5: 759-781.

Théberge, Paul, and Steve Jones. 2003. "Sound Engineering." In Continuum Encyclopedia of Popular Music of the World: Volume II, edited by John Shepherd, 229231. New York: Continuum.

Thompson, Mark. 2008. Lo-fi filmmaker takes stars to street level - CNN. February 19. Accessed October 19, 2014. http://www.cnn.com/2008/SHOWBIZ/Music/02/19/takeaway.shows/.

Tone, Yasunao. 2003. "John Cage and Recording." Leonardo Music Journal 13, no. 1: 11-15.

Truax, Barry. 2001. Acoustic Communication. Westport: Ablex Publishing.

-. 1999. Handbook for Acoustic Ecology. Accessed October 19, 2014. https://www.sfu.ca/ truax/handbook2. $\underline{\mathrm{html}}$.

-. 2012. "Sound, listening and place: The aesthetic dilemma." Organised Sound 17, no. 3: 193-201. https://doi. org/10.1017/S1355771811000380.

Ward, Kim Soleski. 2009. "Musical soundscape: Teaching the concepts of R. Murray Schafer to elementary students." Canadian Music Educator 50, no. 4: 40-42.

Watson, Allan. 2016. "Digital disruption and recording studio diversification: changing business models for the digital age." In Business Innovation and Disruption in the Music Industry, edited by Patrick Wikstrom and Robert DeFillippi, 95-113. Northampton: Edward Elgar Publishing Limited.
Wrightson, Kendall. n.d. "World Forum for Acoustic Ecology - Library." World Forum for Acoustic Ecology. Accessed October 19, 2014. https://ciufo.org/classes/ ae fl13/reading/Intro_AE.pdf.

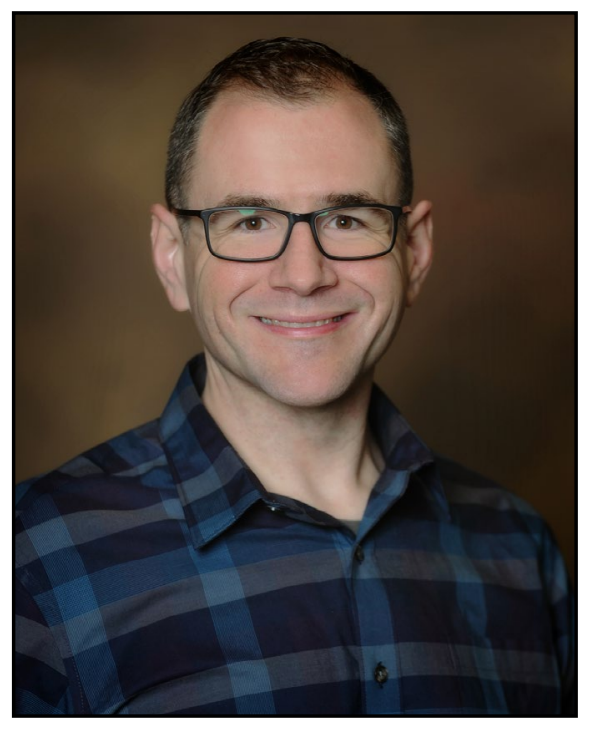

Jon Pluskota is a sound engineer and producer, but considers himself a sound "generalist" as his professional works include traditional music recording projects, mixto-picture works, creative sound design, and experimental sound projects. His recent creative work incorporates both traditional and experimental techniques by expanding upon production practices using artistic approaches in natural and artificial environments to frame the works. His desire is to reinvigorate the sound experience by breaking away from the confines of expectation in the production processes traditionally associated with commercial and artistic sound works. Pluskota received his degrees (B.A., M.A., M.B.A., and Ph.D.) from Southern Illinois University Carbondale and his research interests include applied production practices, aural aesthetics, radio, and the perceptual effects of sound. He recently completed a year abroad at the University of Tartu, Viljandi Culture Academy, as part of the Fulbright Scholar program where he taught sound engineering courses and worked on research while in Estonia. In addition to working on studio and live recordings with regional and national acts, he has also worked as a recordist on a Grammy-nominated recording and has authored several sound-related and pedagogically-focused grants. 


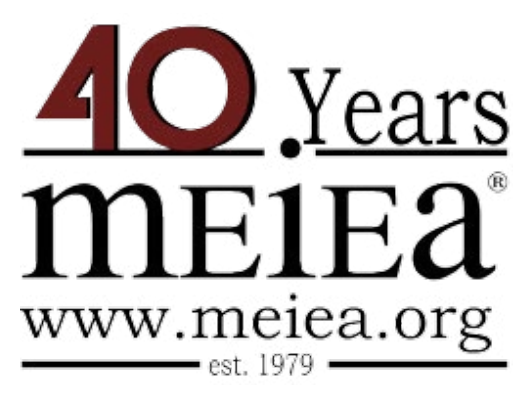

\section{PROCEEDINGS OF THE \\ 2019 INTERNATIONAL SUMMIT \\ OF THE \\ MUSIC \& ENTERTAINMENT \\ INDUSTRY EDUCATORS \\ ASSOCIATION}

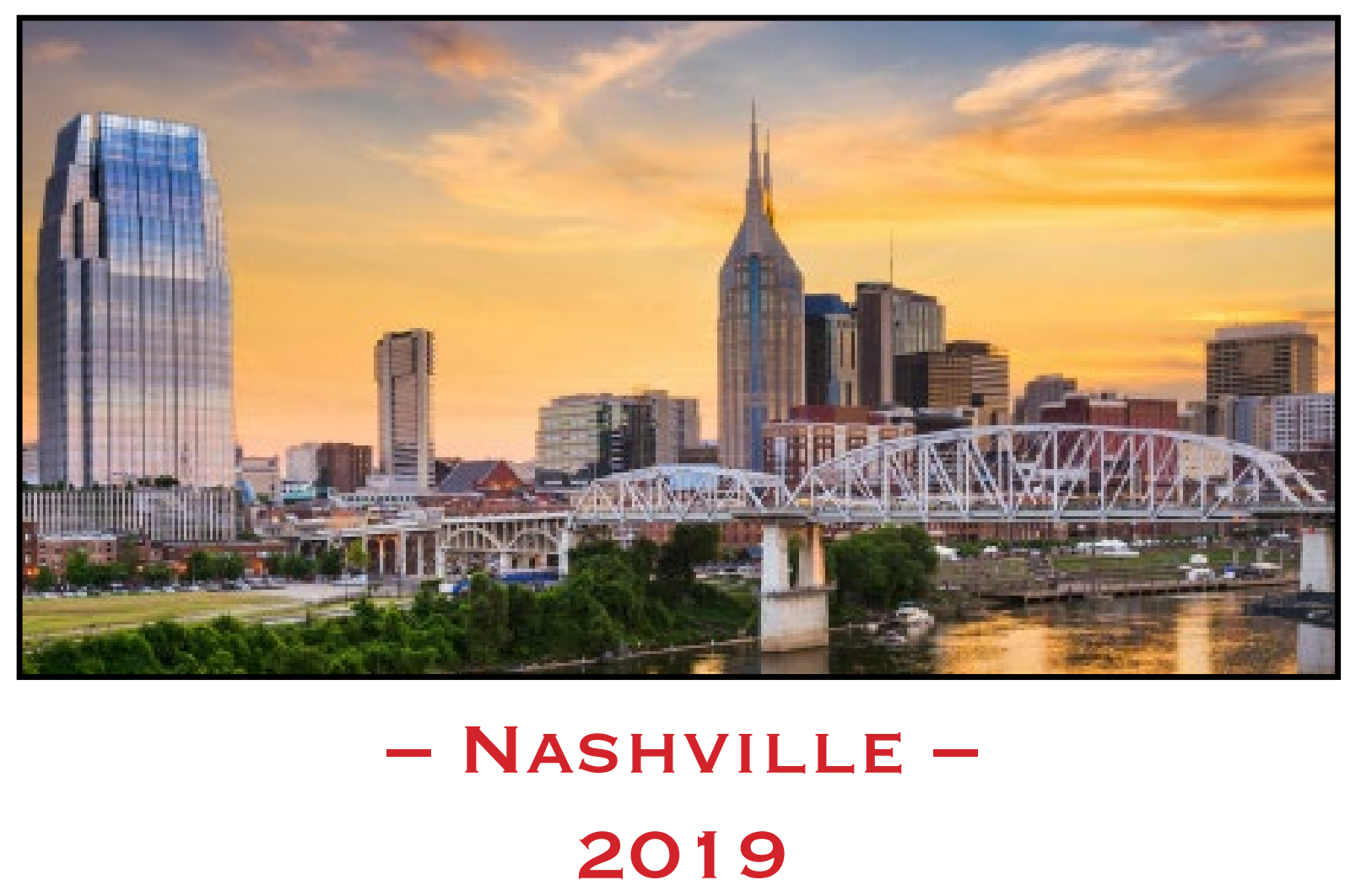

March 21 - 23, $2019 \cdot$ Belmont University - Nashville 